\title{
Chronic Large Thrombus in Major Pulmonary Arteries; Trans Thoracic Echocardiographic Images
}

\author{
Sharada Kalavakolanu* and Meenakshi K \\ Saveetha Medical College and Hospital, Chennai, India
}

Received: 01 December, 2017; Accepted: 04 December, 2017; Published: 05 January, 2018

*Corresponding author: Sharada Kalavakolanu, Saveetha Medical College and Hospital, Chennai, India. E-mail: drsharadaep@gmail.com

We present trans thoracic echocardiographic images of chronic large thrombus in major proximal pulmonary arteries in a 60 year old male.

A 60-year old man presented to our cardiology outpatient services with progressive breathlessness and pedal edema of many months duration. He was cachexic, had systemic desaturation ( $47 \%$ oxygen saturation on pulse oximetry), pulse rate of 90/minute, elevated jugular venous pressure, pitting pedal edema and tender hepatomegaly. His ECG showed right axis deviation, evidence of right atrial enlargement and right ventricular hypertrophy. His transthoracic echocardiogram showed dilated right atrium, right ventricle, main and proximal branch pulmonary arteries. There was large organized thrombus well seen in left pulmonary artery as well as distal right pulmonary artery. (Figure 1,2, 3).

Patient was treated with diuretics and anticoagulation and was unwilling for any further investigation.

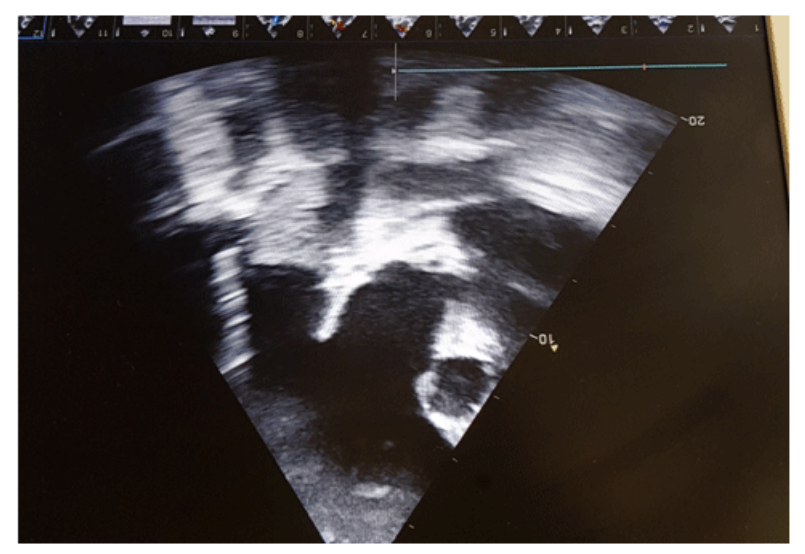

Figure 1: Left Pulmonary Artery

Copyright: (c) 2018 Sharada K, et al.

Citation: Sharada K, Meenakshi K (2018) Chronic Large Thrombus in Major Pulmonary Arteries; Trans Thoracic Echocardiographic ImagesCardiovascular Thoracic Surgery 3(1):1-1. DOI: 10.15226/2573$864 \mathrm{X} / 3 / 1 / 00130$

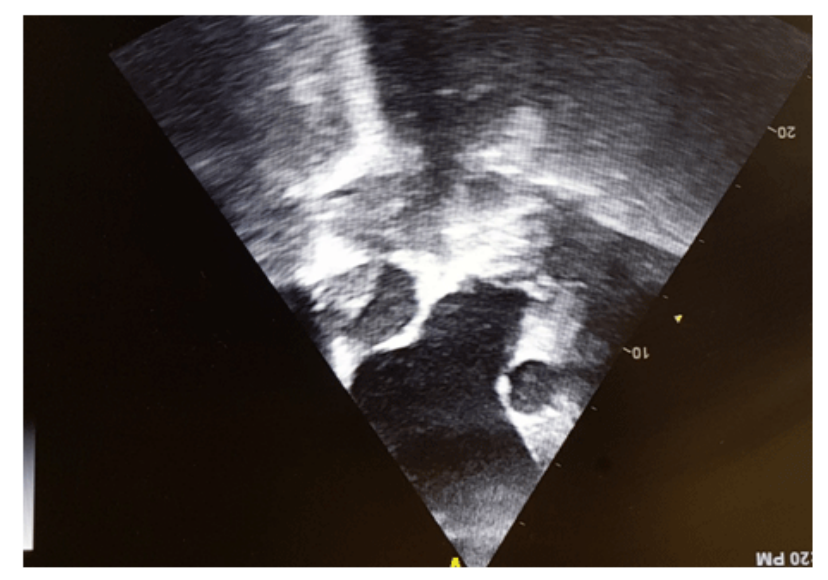

Figure 2: Distal right pulmonary artery

Figure 3:

\section{Reference}

1. Presti B, Berthrong M, Sherwin RM. Chronic thrombosis of major pulmonary arteries. Hum Pathol. 1990;21(6):601-606. 